them were domesticated, though some human remains from neighbouring tumuli and interments are reported on by Dr. Pruner-Bey. The animals whose bones occurred are described as ox (possibly domesticated), pig, stag, sheep, goat, and horse, which is rare. The bones are not always broken, and the vertebræ occasionally occurred in juxtaposition, as if meat at times had been extremely abundant. There is no mention of any remains or traces of dogs, and this condition of the bones seems to afford an argument in favour of their absence, which, if established, would be a remarkable fact. Some teeth of reindeer are mentioned as having been found on the plateau, and it would be of great interest to ascertain their relation to the other remains. Let us trust that ere long there may again be a season in France when a though may fairly be bestowed on other camps and other earthworks than those on which attention is now so unfortunately concentrated.

J. E.

\section{SPONTANEOUS GENERATION}

T HAVE repeatedly subjected various solutions for Dr. Bastian I to a temperature of $150^{\circ}$ to $156^{\circ} \mathrm{C}$. in sealed vacuous tubes; in order that he might afterwards submit them to a microscopical search for living organisms. The result of this search led him to conclude that living organisms had been generated from non-organised matter, whilst Professor Huxley, who examined the contents of one of the tubes, considered that no such conclusion could be drawn from his own observations. I therefore determined to repeat these experiments, operating in exactly the same manner as before in the preparation of the solutions, the sealing them up in vacuous tubes, and exposing them to a high temperature, but taking additional and much more stringent precautions against the subsequent admission of atmospheric germs into the tubes.

For this purpose four tubes of hard Bohemian glass were prepared, and about half-filled with a liquid consisting of

Carbonate of Ammonia . . . 15 grains.

Phosphate of Soda. . . . 5 grains.

Distilled Water. . . . . I oz.

No care was taken to exclude living germs from these ingredients, reliance being placed, for the destruction of their vitality, upon the high temperature to which they were afterwards subjected.

These tubes were carefully exhausted by means of the Sprengel pump, and hermetically sealed; they were then, on July 18 , 1870 , exposed for four hours to a temperature varying from $155^{\circ}$ to $\mathrm{r} 60^{\circ} \mathrm{C}$. in a Papin's digester. After being allowed to cool, the digester was opened, and the tubes immediately plunged, two of them into colourless concentrated oil of vitriol, and the remaining two into a nearly colourless saturated solution of carbolic acid in water. These precautions were taken in order to avoid the possible admission of atmospheric germs through invisible cracks in the glass; such cracks, entirely invisible to the eye, are known sometimes to exist, and to be in some cases so excessively minute as to require several days for the admission of enough air to perceptibly impair a torricellian vacuum within. By keeping the tubes entirely immersed in liquids which are immediately fatal to vitality, I hoped to meet any objections that might be raised, in the event of living organisms being subsequently found in the tubes, that the germs of such organisms had gained access to the enclosed liquids through invisible fissures in the glass. On examining them when they came out of the digester, it was evident that the interior walls of the glass tubes had been corroded by the enclosed liquid, and as the tubes had stood upright in the digester, it was easy to see, by the sharp limits of the erosion, the extent to which the liquid had expanded under the influence of the high temperature to which it had been exposed.

The cylinders containing the immersed tubes were now maintained at a temperature from $60^{\circ}$ to $75^{\circ} \mathrm{F}$, and were exposed to bright diffused daylight, and sometimes to sunlight, for a period of more than five months.

The liquid in all the tubes became more or less turbid, and in some cases a small quantity of a light flocculent precipitate subsided to the bottom. On the $24^{\text {th }}$ of December last two of the tubes, which exhibited the greatest turbidity, were selected for examination (one of them had been immersed in concentrated sulphuric acid, the other in the solution of carbolic acid). The vacuum was unimpaired, and the liquid in the interior formed a good water hammer. These tubes were opened in the presence of Prof. Huxley and Mr. Busk, and we submitted their contents to a searching microscopical examination with powers varying from $\frac{1}{3}$ th to $\frac{\pi}{16}$ th. Especially was the flocculent sediment in the tubes subjected to careful inspection. So far as the optical appearances presented by the sediment go, they may be appropriately described in the terms which Dr. Bastian applied to the matter found by him in a solution of like composition and simiarly treated (see NATURE, July 7,1870 , p. 200). "A number of little figure-of-eight particles, each of which was $2 \frac{1}{2000}$ " in diameter, were seen in active movement, even in situations where they could not have been influenced by currents. The portions of the pellicle were made up of large, irregular, and highly refractive protein-looking particles imbedded in a transparent jelly-like material. The particles were most varied in size and shape, being often variously branched and knobbed. There were also seen several very delicate, perfectly hyaline vesicles, about $\frac{1}{20000}$ " in diameter, these being altogether free from solid contents." But the movement of the particles which we observed was obviously mere Brownian motion; and many of the particles were evidently minute splinters of glass. There was not the slightest evidence of life in any of the particles. The water on the slide containing these solid matters was evaporated off, and they were treated with hot concentrated sulphuric acid, the tem. perature of the slide being raised to about $100^{\circ} \mathrm{C}$. There was no blackening, and the rounded and dendritic bodies remained as entirely unaltered as the glass splinters. Indeed, some of the larger spheroidal bodies were evidently rounded particles of glass which had become detached from the inner walls of the tube by the corrosive action of the enclosed liquid at the high temperature to which it had been exposed in the digester.

London, January 16

E. FrankLAND

\section{LETTERS TO THE EDITOR}

[The Editor does not hold himself responsible for opinions expressed by his Correspondents. No notice is taken of anonymous communications.]

\section{The Continuity of the Chalk}

Sir Charles Lyell devotes a paragraph of his valuable "Students' Elements of Geology," just published, to the consideration of what he regards as a "popular error as to the geological continuity of the Cretaceous period." I feel the utmost diffidence in venturing to controvert any opinion of an authority so unrivalled in such questions, but as I believe the first definite suggestion of this view occurs in the report of the Lightning Expedition of 1868 by my friend and colleague, Dr. Carpenter, where it is specially associated with my name, I feel bound to defend so far as I can, or at all events to explain, an opinion which I then held on perhaps somewhat slender grounds, but which further investigation and reflection have since ripened into a firm belief. Sir Charles Lyell says (p. 263) that "certain points of resemblance which the deep-sea investigations have placed in a strong light, have been supposed by some naturalists to warrant a conclusion expressed in these words: 'We are still living in the Cretaceous epoch ;' a doctrine which has led to much 